\title{
Tras los pasos de Verón... Un acercamiento a las nuevas condiciones de circulación del sentido en la era contemporánea ${ }^{1}$
}

\author{
Mario Carlón' \\ https://orcid.org/0000-0002-5303-1308 \\ I - Facultad de Ciencias Sociales - Instituto Gino Germani \\ Buenos Aires, Argentina
}

Resumen: El trabajo se propone retomar aportes de la obra de Eliseo Verón, en particular sus teorías de la mediatización, de la circulación del sentido y de los grandes "enunciadores sociales" (medios, instituciones, colectivos de actores e individuos). Sostiene que Verón realizó una caracterización de la modernidad y la posmodernidad en esos niveles. Y propone un dispositivo analítico para estudiar la dimensión temporal y espacial de la circulación contemporánea, en la que el sentido "viaja" de las redes sociales mediáticas a los medios masivos y de los medios masivos a las redes sociales. También sostiene que las nuevas formas de circulación deben ser privilegiadas para comprender como está cambiando nuestra cultura mediática.

Palabras clave: mediatización; circulación; sentido; Verón.

Abstract: Following the steps of Verón... an approach to the new conditions of circulation of meaning in the contemporary era - The paper reviews Verón's work, in particular his theories of mediatization, of the circulation of meaning (communication) and of enunciators and enunciatees (institutions, media, collectives of individual actors and individuals). It maintains that Verón made an sharp characterization of the modern and postmodern situation at these levels and it proposes an analytical device to study the spatial and temporal dimension of contemporary circulation, in which content "travels" from social networks to the mass media and from the mass media to social networks. He also argues that it is

1 Este artículo fue escrito para el volumen de homenaje a Eliseo Verón publicado en la Revista Communication \& langages 2018/2 ( $N^{\circ}$ 196). No ha sido publicado anteriormente en portugués ni en español. Referencia: CARLÓN, Mario (2018): "Sur les traces de Verón. Une approche aux nouvelles conditions de circulation du sens dans l'ère contemporaine" Communication \& langages, № 196, Paris, CELSA - Univ. Paris-Sorbonne, 4, I NecPlus, elSSN 1778-7459, DOI 10.3406/colan. Disponible en https://www.cairn.info/revue-communicationet-langages-2018-2.htm 
the new conditions of circulation of meaning that should be focused to account for how our media culture is changing.

Keywords: circulation; mediatization; meaning; Verón.

...la situación de "ser citado por otros, me ha producido siempre algo así como una inquietante extrañeza. Aunque pueda haber algún ingrediente personal en esto, creo que la inquietante extrañeza es, para un autor de textos, uno de los efectos estructurales de las condiciones de reconocimiento, es decir, de la retoma de sus textos por otros. De la retoma, no de la cita de pura forma. La distancia que así se vuelve visible, es a la vez perturbadora, inevitable y creativa"

(Eliseo Verón, 2004: 11)

\section{Escribir sobre Eliseo Verón}

El acto de escribir un texto para un volumen de homenaje a Eliseo Verón conlleva ciertas cuestiones a enfrentar y despejar. Como siempre sucede en estos casos por un lado se encuentra el hombre, su persona y su actividad profesional. Y por otro lado, su obra. Y como siempre también, estas esferas no son tan fáciles de separar (menos hoy).

Al hombre, tuve la oportunidad de conocerlo. Es alguien a quien aprecié mucho y que fue muy generoso conmigo. Pero no haré referencia aquí a su persona, a sus gestos, o a las polémicas que sus actividades profesionales supieron despertar. Creo que a Verón no le habría interesado o que directamente habría desaprobado que me ocupara del hombre en un volumen que lo tiene como objeto de homenaje.

Pero tampoco se trata de lo que hubiera pensado o no Verón. Se trata, ante todo, de lo que con su obra vengo haciendo desde hace años y de lo que en este texto me propongo hacer. Gesto que podrá calificarse como homenaje o no de acuerdo a cómo esa palabra sea interpretada.

Uno de los sentidos de la palabra homenaje, según el Diccionario de la Real Academia Española, es sumisión o veneración. En las relaciones entre textos y autores tiendo a interpretar que los vínculos basados en la sumisión o en la veneración llevan directamente a la aplicación. Es decir, que un autor que venera a otro intentará aplicar su teoría a los problemas que el autor que la enunció consideró e incluso a otros, dado que es probable que la veneración tienda a convertir la obra del autor de referencia en una especie de Biblia, en el sentido en que se suele decirse que es un texto que contiene todas las repuestas.

En el otro extremo se encuentra, quizás, el vinculo que Eliseo Verón identificó en un volumen publicado en homenaje a Emile Benveniste al que hizo referencia en su último libro. Dice que "los trabajos (reunidos en esa compilación) tienen poco que ver con 
las posiciones de Benveniste, y el homenaje fue apenas un pretexto para que los autores desarrollaran sus propias problemáticas". ${ }^{2}$

Entre ambos extremos podría ubicarse, tal vez, una relación basada en otro sentido de la palabra homenaje, que es respeto. La operación que en este texto se va a instalar es, al menos para este autor, un homenaje a Eliseo Verón. Ahora bien, el respeto puede manifestarse de muchas formas. Una de ellas es, por ejemplo, cuando se cita a un autor refiriéndose a él como autoridad sobre un tema puntual. En el caso de Verón podría ser, por ejemplo, sobre la semiosis social o sobre mediatizaciones. Si bien Verón es obviamente una referencia autorizada, no es ésta la operación principal que el lector se va a encontrar en este texto. Si hubiera que buscar una palabra para describir la operación que me propongo llevar a cabo la más adecuada probablemente sea apropiación. Una apropiación implica siempre una retoma y, por lo tanto, una resignificación, que puede desplegarse de múltiples formas. ${ }^{3}$ En este caso se retoman un conjunto de tesis enunciadas por Eliseo Verón sobre las diferencias a nivel de la mediatización y la comunicación entre modernidad y posmodernidad a partir del convencimiento de que sus proposiciones no sólo fueron acertadas, sino que establecieron un camino de reflexión fecundo y, por lo tanto, pueden ser retomadas. Pero como el objeto del cual me voy a ocupar es otro, el momento en que vivimos, al que siguiendo a distintos autores se lo denomina contemporáneo, en el que el sistema mediático y las condiciones de circulación han sufrido una fuerte transformación, se desplegaran también nuevas hipótesis.

\section{Cuatro grandes campos teóricos}

La obra de Eliseo Verón fue y sigue siendo relevante para pensar un conjunto de problemáticas específicas de la era actual. La principal razón por la que se puede sostener esta afirmación es por un rasgo que ha sido poco destacado, que es el hecho de que su reflexión sobre las transformaciones que afectaron a la sociedad posmoderna, de la cual fue un agudo observador - no es un hecho menor que muchos de sus textos más importantes los escribió entre los ochenta y los noventa - tuvo un carácter sistémico. Al decir esto me refiero a que Verón no sólo teorizó sobre un conjunto de cuestiones que caracterizan a la relación medios/sociedad, sino a que cada uno de esos desarrollos se encuentra sólidamente articulado con otros. Por eso, pese a que Verón es reconocido

2 Eliseo Verón, "Binarismo y triadismo", La semiosis social, 2. Ideas, momentos, interpretantes, Buenos Aires, Paidós, 2013, pp. 77.

3 El hecho de que hay una apropiación es lo que pretende sugerirse con la palabra "tras", que se encuentra en el titulo de este artículo. Tras quiere decir después de, a continuación de, en un sentido espacial pero también temporal. Este texto sigue los pasos de las teorías de Verón, pero indefectiblemente viene después de sus últimos textos. Y si en toda retoma o apropiación, incluso en el Quijote de Pierre Menard, hay una resignificación, como explicó muy bien Arthur Danto (en "Tres Cajas Brillo. Cuestiones de estilo", Estética después del fin del arte. Ensayos sobre Arthur Danto, Madrid, Machado Libros, 2005, pp. 19-40), debe darse por descontado que esa operación también se encuentra presente (incluso tal vez contra las intenciones de este au-tor) en este escrito. 
principalmente semiólogo por su teoría sobre la producción social del sentido a partir de uno de sus libros más famosos, La semiosis social. Fragmentos de una teoría de la discursividad debe considerarse que esa teoría no fue la única que desarrolló ni tampoco, probablemente, la más importante o la que más influencia ejerció. ${ }^{4}$

Hay, al menos, otros tres importantes campos en los que Eliseo Verón realizó significativos aportes que se encuentran articulados teóricamente entre sí. ${ }^{5}$ El primero es el de los estudios a los que solía referirse bajo el rótulo mediatización. En una serie de textos claves de los años ochenta ${ }^{6}$, construyó una singular tesis sobre la mediatización (y su historia) que brindó un diagnóstico sobre la época en un momento de cambio de rol de los medios en la vida social. Así su diferenciación entre sociedades mediáticas (modernas) y mediatizadas o en vías de mediatización (posmodernas) es una distinción crucial para cualquiera que no se conforme con estudiar solo los medios, sino que pretenda llegar a un diagnóstico acerca de cómo vincular en cada período histórico medios y sociedad. Según Verón una sociedad mediática (moderna) es aquella en la que los medios operan en base a una lógica representativa y, por lo tanto, funcionan como "espejos" de lo real (más o menos deformantes, dice Verón, poco importa). En cambio, una sociedad mediatizada (posmoderna) es aquella en la que "el funcionamiento de las instituciones, de las prácticas, de los conflictos, de la cultura, comienza a estructurarse en relación directa con la existencia de los medios" ${ }^{\prime \prime}$, cada vez más conceptuados productores de sentido.

En segundo lugar se encuentra el hecho de que Eliseo Verón elaboró un influyente modelo para pensar la comunicación, basado en la noción circulación. En un contexto en el que aún ejercía influencia la concepción comunicacional que Verón consideraba moderna ${ }^{8}$ sintetizada en el campo de los análisis discursivos por el modelo de Roman Jakobson", la introducción del concepto "circulación", que insistió en el desfase entre producción y reconocimiento, le permitió reflexionar con solidez sobre distintos temas

4 El desarrollo que en estos años ha tenido en América Latina la perspectiva mediatizaciones, una de cuyas corrientes retoma la obra de Eliseo Verón, es un claro síntoma de lo que se está señalando.

5 En este texto se distinguen cuatro campos teóricos presentes en la obra de Verón y se van a incluir ciertos escritos en un campo y otros en otro. Rápidamente, establecemos dos comentarios sobre esta situación. El primero es que, obviamente, muchos escritos de Verón articularon varios campos teóricos. Por consiguiente, si un texto aparece categorizado como emblemático de uno de ellos y no en otro es, principalmente, por la focalización que en determinado momento de la exposición se está realizando. El segundo es que se identifican los textos que este autor conoce, pero dada la magnitud de la obra de Verón, que se extiende por décadas y en distintos idiomas, y el hecho de que actualmente se está llevando a cabo una revisión de su archivo, sería lógico que en un futuro próximo deban establecerse ajustes y recategorizaciones (por ejemplo, que el primer texto que escribió sobre tal tema lo haya escrito antes, etcétera).

6 Dos de esos textos son: Eliseo Verón "El living y sus dobles. Arquitecturas de la pantalla chica", El cuerpo de las imágenes, Buenos Aires, Norma, (2001 [1984]), pp. 13-40 y "La mediatización", Semiosis de lo ideo-lógico y el poder/La mediatización, Buenos Aires, FFyL, (1995 [1986]), pp. 39-132.

7 Eliseo Verón, "El living y sus dobles. Arquitecturas de la pantalla chica", El cuerpo de las imágenes, Buenos Aires, Norma, (2001 [1984]), p. 15.

8 Al respecto puede consultarse "Posmodernidad y teorías del lenguaje: el fin de los funcionalismos", en Fragmentos de un tejido, Barcelona, Gedisa, (2004 [1985]), 61-68.

9 Tal como aparece expuesto en: Jakobson, Roman, "Lingüística y poética", Ensayos de lingüística general, Barcelona, Seix Barral, (1981 [1960]), pp. 347-395. Más allá de importantes diferencias lo señalado es válido, también, para otros modelos de la época de Verón, como el de Kerbrat-Orecchioni (expuesto en: KerbratOrecchioni, Catherine, "La problemática de la enunciación", La enunciación. De la subjetividad en el lenguaje, Buenos Aires, Hachette, (1997 [1986]), pp. 17-44). 
que caracterizaron al debate posmoderno, por ejemplo, la crisis de las instituciones (los partidos políticos, los medios de comunicación masiva, las marcas, etcétera).

Y en tercer lugar se encuentra el aporte que Verón realizó a los estudios discursivos a partir de un interés que lo acompañó a lo largo de su vida: la articulación entre semiótica y sociología. Verón fue, quizás, el más sociólogo de los semiólogos. Y desde que introdujo nociones como colectivo ${ }^{10}$ el interés acerca de cómo la semiótica de medios podía alcanzar un sólido fundamento sociológico nunca lo abandonó. Podemos identificar este campo, uno de los principales de su reflexión, bajo el título socio-semiótica de los enunciatores y enunciatarios.

En este texto me voy a detener menos en el desarrollo más conocido, en el de la semiosis social, y más en los otros, en sus teorías sobre la mediatización, sobre la circulación del sentido (comunicación), y en la socio-semiótica de los enunciadores y enunciatarios. Lo que intentaré en el ítem 3, es retomar las tesis principales de Verón y establecer en qué se diferencia la situación contemporánea de la moderna y la posmoderna ${ }^{11}$. Luego de presentar una tesis sobre el cambio en la mediatización en 3.1., mostraré en 3.2. el gráfico sobre la circulación que Verón presentó en "El sentido como producción discursiva" en 1987a, que durante décadas ha sido utilizado en América Latina para explicar cómo funciona la comunicación y del que he partido para diseñar los esquemas que presentaré más adelante. Enseguida agregaré en este nivel una dimensión analítica: las direcciones de la circulación, que son la descendente, la horizontal y la ascendente, y presentaré un gráfico de cómo podrían haberse representado, sumando esta dimensión, los procesos comunicacionales característicos de la modernidad y la posmodernidad. En 3.3. me referiré a la socio-semiotica de los enunciadores y enunciatarios e incorporaré esta dimensión a un gráfico "síntesis" de lo desarrollado

10 Esta noción aparece ya en "La palabra adversativa. Observaciones sobre la enunciación política", en El discurso político. Lenguaje y acontecimientos, Buenos Aires, Hachette, 1987, 13-26. Luego recibirá una aguda discusión, a partir de una retoma de la obra de Alessandro Pizzorno, en "Mediatización, comunicación política y mutaciones de la democracia". Semiosfera 2, 1994, pp. 5-36.

11 Dos observaciones. Por un lado, que este señalamiento no implica, de ningún modo, que Verón no haya realizado aportes en estos últimos años para pensar la situación contemporánea. Indica tan sólo que no postuló en forma categórica ni sistémica, retomando sus propias proposiciones sobre la modernidad y la posmodernidad, que nos encontramos en un momento diferente. Más allá de cual haya sido la razón por la que no lo hizo (ya sea porque no lo creía o porque no le interesaba en ese momento de su vida el tema) se concentró en otras cuestiones. Eso no impidió que los textos de sus últimos años nos dejaran una serie de reflexiones específicas sobre la sociosemiótica desde un punto de vista no antropocéntrico (que desborda el marco anterior al articularse con la naturaleza como marco de producción de sentido) y, también, el desarrollo de una tesis fundamental para pensar la situación actual de la televisión (la de su crisis o fin), que se reveló fructífera para estructurar una nueva historia de la mediatización.

Por otro lado, que el intento de establecer en qué se diferencia lo contemporáneo de lo moderno y lo posmoderno desde esta perspectiva se realizará siguiendo una serie textos que he dedicado a este tema, entre ellos: "La cultura mediática contemporánea: otro motor, otra combustión. (Segunda apropiación de la teoría de la comunicación de Eliseo Verón: la dimensión espacial), en A circulação discursiva: entre produção e reconhecimento, Castro, Paulo César (org.), Maceió, Edufal, 2017, pp. 25-48; “Una apropiación contemporánea de la teoría de la comunicación de Eliseo Verón", en Comunicación, campo(s) teorías y problemas. Una perspectiva Internacional; Vizer Eduardo y Carlos Vidales (coordinadores), Salamanca, Comunicación social, 2016, pp. 125153 y "Público, privado e íntimo: el caso Chicas bondi y el conflicto entre derecho a la imagen y libertad de expresión en la circulación contemporánea", en Dicotomía público/privado: estamos no camino certo? Paulo César Castro (organizador). Maceió, Edufal, 2015, pp. 211-232. 
en este apartado. Luego, en el ítem 4. expondré brevemente los conceptos claves del dispositivo analítico con el que estamos trabajando en dos espacios académicos en la Universidad de Buenos Aires dedicados a estudiar la circulación contemporánea que va de las redes sociales a los medios masivos y de los medios masivos a las redes sociales ${ }^{12}$, y mostraré una serie de gráficos que son resultados del análisis de un caso emblemático de la nueva circulación.

\section{Mediatización, comunicación y sociedad contemporánea}

\subsection{Mediatización: la emergencia de una sociedad hipermediatizada}

Es importante no subestimar el hecho de que cuando Verón diagnosticó, en la posmodernidad, la diferencia entre una sociedad mediática y otra en vías de mediatización, vivíamos en un solo ambiente mediático: el sistema de los medios masivos. La convivencia de ese sistema con uno nuevo con base en Internet (Twitter, Facebook, Instagram, YouTube, Snapchat etcétera), ha transformado profundamente el paisaje mediático, dando origen a una sociedad hipermediatizada. A la vez, ha habilitado, como veremos, el nacimiento de una profunda transformación de las condiciones de circulación. ${ }^{13}$

Esto no quiere decir que todos los rasgos que caracterizaban a la mediatización posmoderna han desparecido. Por ejemplo, una de las prácticas identificadas por Verón en la posmodernidad, performar en función de la mediatización, que afectó a instituciones y referentes sociales dando origen a fenómenos como la llamada videopolítica, no solo mantiene su vigencia en la sociedad contemporánea sino que, en gran medida, se ha expandido. Hoy no sólo instituciones y celebrities performan en función de la mediatización. Tomarse fotos con el objetivo de ser publicadas luego en las redes sociales como Facebook o Instagram se ha vuelto una práctica cotidiana para miles de millones de nuevos enunciadores en las redes sociales. Pero aún en el marco de esta práctica muchas cosas han cambiado. Es decir que si bien la práctica a grandes rasgos continúa y se ha expandido, la emergencia de nuevos medios (como las redes sociales mediáticas) y condiciones de enunciación, a la par de la emergencia de nuevos enunciadores (los individuos "comunes", Ilamados amateurs, "usuarios", prosumidores, etcétera), están transformando la circulación del sentido.

12 Esos espacios son el Proyecto de Investigación Ubacyt "Lo contemporáneo en la política, las artes y los medios", asentado en el Instituto Gino Germani, y la Cátedra Semiótica de Redes de la Carrera de Ciencias de la Comunicación, ambos de la Facultad de Ciencias Sociales de la Universidad de Buenos Aires. En los equipos participan, entre otros, Damian Fraticelli, Ana Slimovich, Rocío Rovner y Josefina De Mattei. Con el dispositivo analítico que aquí se presenta se están estudiando diversos casos de circulación hipermediática (youtubers, movimientos sociales, casos periodísticos relevantes, etcétera). El sitio de la cátedra es: http:// semioticaderedes-carlon.com/

13 Aunque la crisis de los medios masivos, que se explica porque ya no mantienen a sus públicos cautivos para decirles qué ver, cuándo y cómo (en términos de Verón ya no pueden "programar la vida social") es un hecho real, los medios masivos no han desparecido y aún son relevantes. El tema fue especialmente discutido en un volumen en el que participó Verón, en: Carlón, Mario y Scolari, Carlos A. El fin de los medios masivos. En comienzo de un debate. Buenos Aires, La Crujia, 2009, 267 páginas. 
Pero el cambio es aún mayor. Es un hecho que se vuelve evidente cuando se atiende a que hoy hay una interacción permanente entre el sistema de medios masivos, que ya no es tan dominante como antes pero aún es capaz de marcar la agenda, y el nuevo sistema de medios con base en las redes telefónicas e internet. Esta interacción es uno de los principales rasgos que caracterizan, más allá de la modernidad y la posmodernidad, a la situación contemporánea. Y es una de las principales razones que obliga a pensar que enfrentamos nuevas tareas en nuestro campo de estudios. La circulación del sentido hoy ha devenido hipermediática, lo cual quiere decir que frecuentemente los contenidos "viajan" desde las redes sociales a los medios masivos y desde los medios masivos a las redes sociales. Por eso una acción urgente a desarrollar es empezar a determinar qué sucede cada vez que en la nueva circulación se produce un "punto de encuentro" entre ambos sistemas de mediáticos. Mientras hubo un solo sistema de medios las relaciones eran intrasistémicas (por ejemplo, la radio comentaba a los diarios y a la televisión, todo sucedía a través de referencias inter-discursivas en el marco del sistema de medios masivos). Pero en una sociedad hipermediatizada, en la que conviven dos sistemas de medios con notables diferencias entre sí, estas relaciones han pasado a ser inter-sistémicas y la circulación del sentido ha mutado: porque ha cambiado en su ritmo, en su escala y en su complejidad.

\subsection{Circulación: de la dominancia de una comunicación "descendente" a un estallido de múltiples direcciones comunicacionales}

Los análisis de Eliseo Verón tuvieron por objeto de estudio principalmente a fenómenos comunicacionales propios de la era de los medios masivos. Aunque Verón nunca los nombró de esta forma, es posible decir que esos fenómenos eran "descendentes", es decir, que instalaban procesos comunicativos desde "arriba hacia abajo", desde las poderosas instituciones a los públicos. Es un fenómeno característico de la modernidad que se continúa en la posmodernidad que también posee un solo sistema de medios. Pese a este hecho los gráficos con los que Eliseo Verón ilustró cómo funcionaba la circulación nivelaron producción y reconocimiento, es decir, no ubicaron a la producción "arriba" y al reconocimiento "abajo". Veamos el gráfico que publicó en su clásico texto sobre la semiosis social, probablemente uno de los más citados del autor: ${ }^{14}$

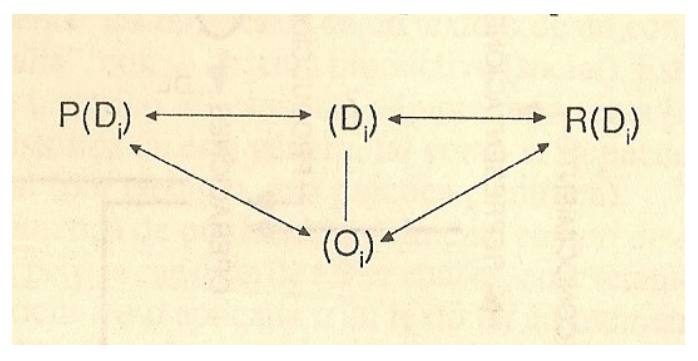

Fonte: Eliseo Verón, 1987.

14 Eliseo Verón, "El sentido como producción discursiva", La semiosis social. Fragmentos de una teoría de la discursividad, Buenos Aires, Gedisa, 1987, p 132. 
El gráfico distingue para un discurso $(\mathrm{D})$, sus condiciones de producción $\mathrm{P}(\mathrm{D})$ y de reconocimiento $\mathrm{R}(\mathrm{D})$. Como señala Verón, la diferencia entre producción y reconocimiento es constitutiva y no quedan huellas de la circulación. ${ }^{15}$ El esquema trabaja con una lógica horizontal: producción y reconocimiento aparecen nivelados. ¿Por qué graficó Verón así la circulación? Es difícil saber la respuesta. Nuestra tesis: porque lo que le interesaba era mostrar que la diferencia entre producción y reconocimiento era universal, funcionaba tanto para situaciones mediatizadas como no mediatizadas e, incluso, para aquellas en las que en producción se encontraba una poderosa institución mediática y en reconocimiento las audiencias o los Ilamados públicos que se componen de individuos.

Ahora bien, debido a que por la modificación del sistema mediático y social a la que venimos haciendo referencia necesitaremos incluir en el análisis de la situación actual a la dimensión direcciones de la comunicación (y así introducir explícitamente, podría decirse, la dimensión del poder), presentamos el siguiente esquema desarrollado con el lenguaje visual veroniano como un modo posible de ilustrar cómo funcionaba de forma dominante la circulación en la modernidad y la posmodernidad, cuando los medios masivos eran instituciones hegemónicas que reinaban sin competencias mediáticas:

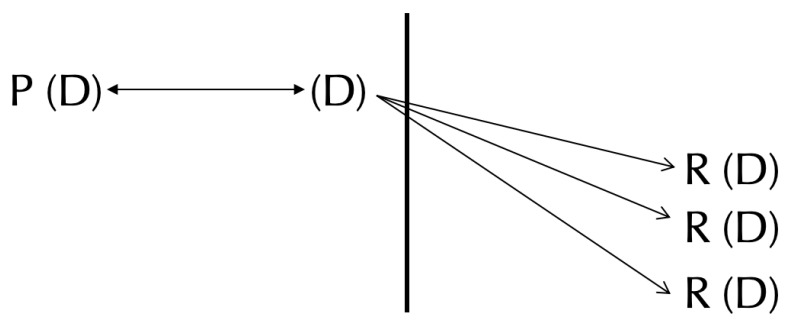

Fonte: Gráfico realizado por Mario Carlón

En el gráfico la diferencia producción/reconocimiento en tanto elemento constitutivo de todo intercambio discursivo se mantiene intacta e, incluso, aparece resaltada con una barra vertical. Se ilustra así que un discurso puede generar múltiples reconocimientos.

15 Dice Eliseo Verón en "El sentido como producción discursiva", La semiosis social. Fragmentos de una teoría de la discursividad, Buenos Aires, Gedisa, 1987, 129: "Estos dos conjuntos no son jamás idénticos (ya hemos insistido en la primera parte de este trabajo sobre este punto): las condiciones de producción de un conjunto de significante no son nunca las mismas que las de reconocimiento. La distancia entre producción y reconocimiento es extremadamente variable, según el nivel de funcionamiento de la semiosis en que uno se coloca, así como según el tipo de de conjunto significante estudiado. No hay, por el contrario, propiamente hablando, huellas de la circulación: el aspecto 'circulación' sólo puede hacerse visible en el análisis como diferencia, precisamente, entre los dos conjuntos de huellas, de la producción y del reconocimiento. El concepto circulación sólo es, de hecho, el nombre de esa diferencia". 
Pero la introducción de la dirección comunicacional "descendente" hace explicito el hecho de que el sentido circulaba desde "arriba" hacia "abajo".

Dicho esto, hemos llegado a una pregunta crucial: ¿cómo podemos graficar y estudiar desde nuestra perspectiva la circulación contemporánea que se despliega en múltiples ritmos y direcciones y que ha alcanzado un alto grado inter-sistémico? Presentar un esquema analítico inspirado en la teoría y los gráficos de Verón que pueda ser utilizado para estudiar distintos casos de circulación constituye desde hace algunos años un objetivo de nuestro trabajo. Pero antes de pasar a explicar cómo estamos desarrollando esa tarea voy a detenerme un momento a explicar cómo se ha modificado en la contemporaneidad la situación contemplada por otro campo analítico considerado por la teoría veroniana: la sociosemiótica de enunciadores y enunciatarios. Conviene, porque luego será mucho más rica y clara nuestra exposición sobre la circulación actual.

\subsection{Sociosemiótica de los enunciadores y enunciatarios: fin de los lugares pre-establecidos. Nuevos enunciadores y funciones}

Es probable que Verón nunca le haya dado un nombre específico a este campo de reflexión. Tal como lo entendemos se ocupa de tres aspectos: a) del estatuto de enunciadores y enunciatarios, es decir, cuál es el estatuto de los que intervienen en el proceso comunicacional), b) del lugar desde el cual intervienen (producción o reconocimiento) y, c) de cuál es su capacidad de construir colectivos. Como quedó claro en algunos textos Verón consideraba en concordancia con ciertos paradigmas de los estudios sociológicos de la época, cuatro grandes categorías de enunciadores y enunciatarios: instituciones, medios, colectivos de actores individuales e individuos. ${ }^{16}$ Durante la modernidad el proceso comunicacional dominante se establecía a partir de una estructura fija: de dispositivos socio-institucionales a colectivos de actores individuales. ${ }^{17}$ Como ya hemos señalado, esta estructura es válida también para posmodernidad, en la que el único sistema mediático vigente eran los medios masivos. Es una estructura que tenía una función, porque según aclaró en su último libro los fenómenos mediáticos desempeñan una doble función en la vida social. Por un lado "son refuerzos fundamentales de la producción y de la estabilidad, a lo largo del tiempo, de colectivos producidos por los subsistemas de un sistema social"18 (es lo que sucedió, por ejemplo, con los programas religiosos televisivos y radiofónicos, que desde su emergencia intentaron reforzar los vínculos que los colectivos mantenían con la institución). Por otro lado "generan

16 Por ejemplo, en "Esquema para el análisis de la mediatización", Diálogos de la Comunicación, №48, Lima, Felafacs, 1997, pp. 9-17.

17 Véase Eliseo Verón, "Lógicas sistémicas sociales y socioindividuales", La semiosis social, 2. Ideas, momentos, interpretantes, Buenos Aires, Paidós, 2013, pp. 292. El hecho de que pusiera instituciones en producción y no en reconocimiento se vio facilitado porque privilegió la recepción individual por sobre la familia como institución en reconocimiento.

18 Eliseo Verón, "Ciclos de vida", La semiosis social, 2. Ideas, momentos, interpretantes, Buenos Aires, Paidós, $2013,422$. 
sus propios colectivos", ${ }^{19}$ por ejemplo, las audiencias televisivas o las actualmente denominadas comunidades de fans. ${ }^{20}$ Podemos hacer una síntesis y graficar lo que venimos señalando en 3.1. y 3.2. respecto a la situación comunicacional que caracterizaba a la modernidad y a la posmodernidad de la siguiente forma:

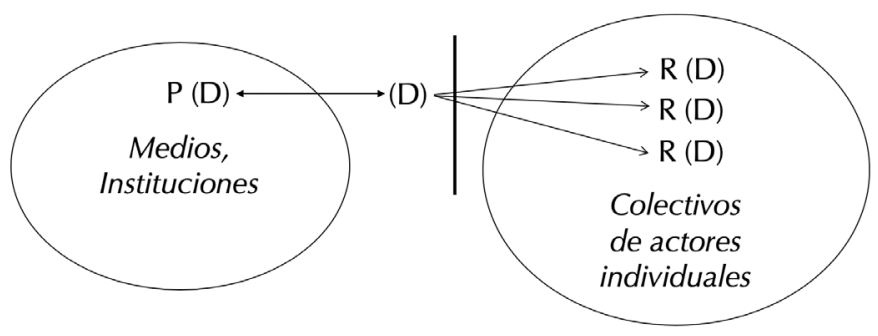

Fonte: Gráfico realizado por Mario Carlón

La introducción de esta dimensión, que completa sucintamente (y esquemáticamente, por supuesto) la revisión que nos proponíamos hacer, nos permitió dar cuenta de cómo conceptualizaba Verón a los procesos comunicacionales dominantes en la modernidad y la posmodernidad. Por otro lado, nos ha permitido comenzar a exponer nuestra tesis: que hoy nos enfrentamos a una escenografía en la que el conjunto de parámetros estabilizados que caracterizaban a esta situación ha mutado. Hay un conjunto de transformaciones caracterizan a la situación contemporánea. Situación que genera la emergencia de nuevas preguntas en todos los niveles en los que nos hemos concentrado. Es imposible intentar dar cuenta de muchas de ellas en este texto, pero al menos intentaremos atender a algunas de las principales.

19 Idem.

20 El modo en que se construyen colectivos a través de la mediatización es uno de los temas más importantes de la actualidad. El hecho de que Verón prácticamente sólo haya considerado explícitamente que los colectivos los producen las instituciones o los medios no debería ser un impedimento para el desarrollo de este campo de estudios. En este tema nuestra posición es que un rasgo que caracteriza a la situación contemporánea y que ha alcanzado gran complejidad gracias a la circulación hipermediática es la construcción de colectivos por parte de actores individuales que acceden fácilmente a medios individuales a través de las redes sociales mediáticas. Para sostener mejor lo que estamos diciendo podemos citar un texto que dedicamos a un proyecto fotográfico amateur, Chicas bondi, que dio origen a nuestros estudios sobre circulación, en el que un fotógrafo individual anónimo (luego se supo su identidad: era un joven sin antecedentes importantes en el campo artís-tico o el mediático) construyó un colectivo de seguidores a lo largo de varios años a través de distintas plataformas (Facebook, Instagram, tumblr, Twitter). El texto es el siguiente: Carlón, Mario. "Público, privado e íntimo: el caso Chicas bondi y el conflicto entre derecho a la imagen y libertad de expresión en la circulación contemporánea", en Dicotomía público/privado: estamos no camino certo? Paulo César Castro (organizador). Maceió, Edufal, 2015, pp. 211-232. 


\section{Un propuesta para el análisis de circulación contemporánea}

A partir de aquí se expondrá tal como se adelantó un dispositivo analítico inspirado en el lenguaje de Verón diseñado para analizar las nuevas condiciones de circulación que caracterizan a la hipermediatizada sociedad contemporánea. El acento estará puesto en fenómenos de circulación del sentido hipermediáticos, que van desde las redes sociales a los medios masivos y desde los medios masivos a las redes sociales.

La exposición se dividirá en dos partes. En la primera se expondrá la dimensión temporal del análisis y se mostrará cómo se retoma el análisis veroniano para dar cuenta de casos de circulación del sentido ascendentes, específicos de la contemporaneidad (casos que vienen desde "abajo hacia arriba", desde las redes sociales a los medios masivos). Se realizarán algunos comentarios y enseguida se pasará a un gráfico "síntesis de análisis" de un caso que se ha elegido para ejemplificar. El caso es el Ilamado por los medios argentinos "Massa/Taj ahí", una serie de videos que subió en 2014 a YouTube el candidato presidencial Sergio Massa que fueron retomados y burlados en las redes sociales y luego comentados por los medios masivos.

En la segunda parte se expondrá la dimensión espacial y se retomará la sociosemiótica de enunciadores y enunciatarios para construir "geografías espaciales", escenarios que permitirán ilustrar cómo distintos enunciadores se posicionan, en cada fase, ante determinados discursos.

\subsection{La dimensión temporal}

\subsubsection{Presupuestos del dispositivo analítico para el análisis temporal de la circulación hipermediática}

El dispositivo analítico con el que trabajamos divide el espacio en dos grandes áreas mediáticas, la de arriba representa al sistema de medios masivos, la de abajo al nuevo sistema de mediatización con base en redes telefónicas e internet (redes sociales). La circulación puede ser, como se señaló, de dos tipos, intra-sistémica o inter-sistémica. Es intra-sistémica cuando acontece en el seno de uno de los dos sistemas mediáticos, en el de los medios masivos o en el del nuevo sistema de mediatización. E inter-sistémica cuando el sentido "viaja" de un sistema a otro, hacia arriba o hacia abajo.

A la vez, como el proceso se despliega en el tiempo y el dispositivo analítico pretende contar la "película" de la circulación, distingue fases. La primera Fase identifica siempre el origen de la circulación y puede ser ascendente o descendente. Como el discurso (D) es un fenómeno material, las condiciones de producción, que son anteriores, se ubican arriba o debajo de la línea que demarca a los espacios mediáticos. Cuando los discursos son ascendentes, luego de la materialización de D es común que se produzcan intercambios 
horizontales con pares que dan "me gusta", comentan, o se manifiestan de otras formas de acuerdo a las posibilidades que les permite la red mediática que están utilizando. De ahí en adelante se identifican fases cuando se producen cambios de escala en la mediatizacion, es decir, cuando un discurso que viene desde las redes es retomado por los medios masivos o viceversa. Hablamos entonces de circulación hipermediática. Pero si en la circulación intrasistémica suceden procesos significativos se los identifica bajo el nombre subfase. Pasemos rápidamente a un caso analizado que va a permitir visualizar rápidamente lo que se está señalando.

\subsubsection{El caso "Taj ahí", una campaña del candidato Presidencial Sergio Massa}

El siguiente es el gráfico que muestra lo acontecido con una campaña de un candidato Presidencial en la Argentina, Sergio Massa, desde fines de 2014 cuando subió una serie de videos dedicados a los ciudadanos de distintas provincias a YouTube hasta que apareció personalmente en un conocido y popular programa de televisión abierta en el que le preguntaron qué opinaba de lo que había sucedido con esos videos en las redes sociales mediáticas.

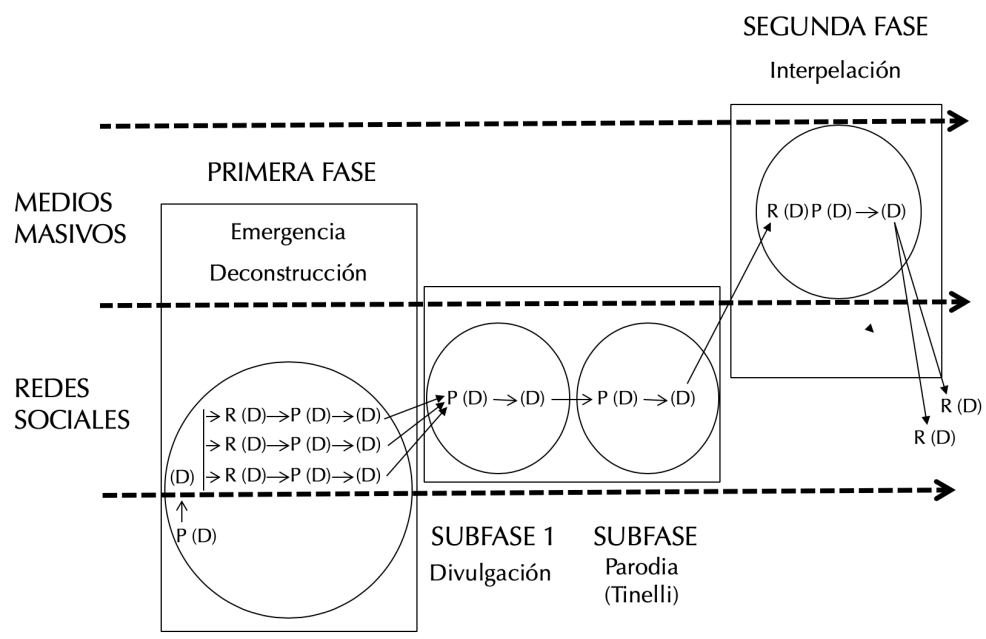

Fonte: Gráfico realizado por Mario Carlón

La Primera Fase ilustra el inicio de la circulación y se la denomina Emergencia/ Deconstrucción (se les ha puesto nombres distintos a las fases para evidenciar que en cada una domina un proceso de producción de sentido específico). Desde una cuenta en YouTube del candidato Sergio Massa se suben una serie de videos destinados a distintos "colectivos" provinciales (como "correntinos", "neuquinos", etcétera) con mensajes 
específicos. ${ }^{21}$ Esos discursos comienzan a tener recepción en las redes sociales y son graficados en su proceso $R(D)-P(D)$ - (D). Entre los discursos que retoman los videos de Massa nos interesa destacar, por un lado, un video subido a YouTube por un enunciador poco conocido (Alpataco) que se burla de la forma en que habla Massa: destaca que dice "taj ahí" en vez de "estás ahí" (la frase completa es: "Te hablo a vos, que taj ahí") y lo presenta como un impostor, alguien que pretende hablar en "provinciano para provincianos". ${ }^{22}$ Por otro lado, una serie extensa de tweets producidos por distintos enunciadores (muchos de ellos fakes, algunos desconocidos, otros no) que producen "nuevos discursos", cada uno de los cuales enuncia humorísticamente que es un "nuevo spot de Massa" dedicado a una comunidad especifica. Así se autodenominan "el spot de Massa para la comunidad menonita", "para los fanáticos de Star wars", etcétera. Cada uno de ellos viene acompañado de una ilustración: una especie de meme que es un fotomontaje en el que aparece Massa vestido con ropa característica de cada colectivo (más abajo incluimos un solo ejemplo de la gran cantidad que se produjeron de este tipo). Si el video de Alpataco subido a YouTube construía a Massa como un impostor lingüístico, en estos discursos se pone a la luz la estrategia política de dirigirse a distintos colectivos Ilevándosela al absurdo. Este conjunto de discursos constituyen la Primera Fase de la circulación.

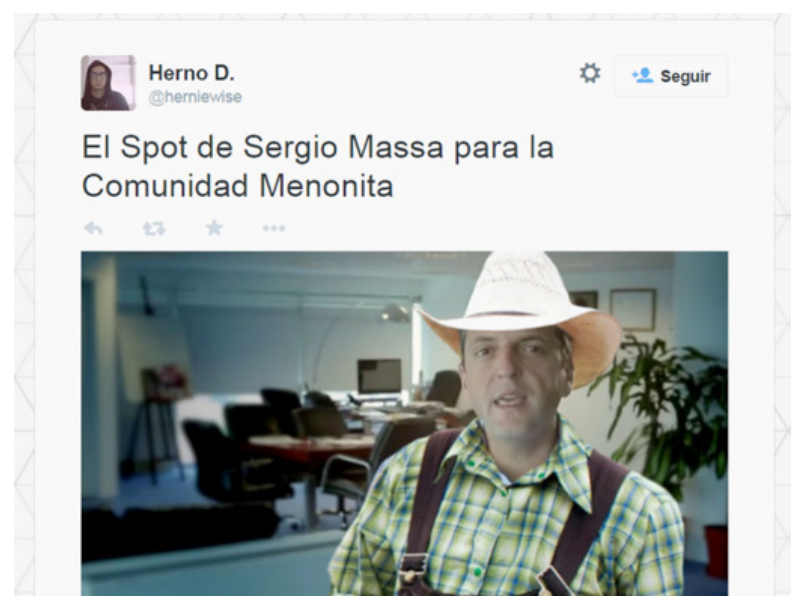

Luego se grafican dos Subfases. Son momentos significativos de la circulación, pero intra-sistémicos porque los contendidos no pasan del sistema de redes sociales al de los medios masivos. Los enunciadores son otros. En la primera subfase, Ilamada Difusión, agrupamos a medios digitales (portales, diarios) que difunden y comentan

21 Uno de ellos, disponible en: https://www.youtube.com/watch?v=r-ATfZtxfvo.

22 Video subido por Alpataco: https://www.youtube.com/watch? $=y W B m D d M 2 v h Y$. 
lo que está sucediendo en las redes: de qué modo los videos de Massa están siendo tratados humorísticamente. En la segunda subfase, Ilamada Parodia, incluimos un video subido por Marcelo Tinelli, conductor del programa con más rating de la televisión abierta, a su canal personal de YouTube. ${ }^{23}$ El video es una parodia performada por un humorista del programa que construye una actuación a partir de los spots de Massa y de los tweets subidos a la red. El humorista aparece representando a distintos personajes con la cara de Massa (un fan de los Rolling Stones, un jugador de futbol brasileño, etcétera) que habla con el modismo que según el primer video lo caracteriza como un impostor: "Taj ahí".

Luego el gráfico muestra la Segunda Fase, denominada Interpelación, que ya es hipermediática (inter-sistémica) porque ahora lo acontecido es retomado por los medios masivos. Esto sucede cuando Massa se presenta en un clásico programa de la televisión abierta conducido por una célebre conductora Ilamado "Almorzando con Mirtha Legrand". En él la conductora consulta al candidato presidencial por lo sucedido en las redes sociales en relación a sus videos. Le dice que a ella no le gusta que la ridiculicen y se solidariza con él. Y muestra el video paródico subido por Tinelli a YouTube al público y a los demás invitados para que Massa lo comente. Massa dice que no le molesta la imitación, que hay que tener sentido del humor ${ }^{24}$.

Comentarios. El grafico intenta ilustrar un nuevo caso de circulación discursiva, en la que el contenido pasa de las redes sociales mediáticas a los medios masivos produciéndose cambios de sentido entre fase y fase. En esta circulación se producen, como mínimo, tres procesos de cambio de sentido. En primer lugar hay un cambio en la escala de la mediatizacion ${ }^{25}$ : vemos cómo un discurso que nace en una cuenta en YouTube se divulga y llega hasta los medios masivos. En segundo lugar hay cambios que afectan al estatuto del enunciador: así Massa como enunciador sigue interpelando a colectivos específicos (pro destinatarios) ${ }^{26}$ en las redes sociales, pero a la vez debe articular una estrategia dirigida a contra-destinatarios debido a que tiene que responder porque fue caracterizado como un impostor especulativo. En tercer lugar se produce a lo largo de todo el proceso una complexificacion en las direcciones comunicacionales: Massa produjo discursos para colectivos provinciales en las redes sociales que siguen circulando, pero tambien debe dar explicaciones a una celebrity y su gran público en un programa de televisión abierta. Es decir, comunicó desde "abajo" y tuvo que dar explicaciones desde "arriba".

23 Video subido por Tinelli: https:/www.youtube.com/watch?v=8gC8A1C34F4\&t=98s

24 Momento de la intervención de Massa en el programa de Mirtha Legrand: https://www.youtube.com/ watch?v=y2YLC08CLCA.

25 Que hay procesos de cambio de escala es uno de los rasgos principales de los procesos de mediatización.

26 Seguimos aquí el análisis que Eliseo Verón realizó del discurso político en "La palabra adversativa. Observaciones sobre la enunciación política", en El discurso político. Lenguaje y acontecimientos, Buenos Aires, Hachette, 1987, 13-26, en el que distinguió un enunciador y tres enunciatarios a los que llamo pro-destinatario (aquel que comparte las posiciones del enunciador, con quien mantiene una posición de refuerzo), contra destinatario (aquel que mantiene un vínculo basado en la desconfianza y en la polémica) y el para-destinatario (con quien mantiene una posición de persuasión). 


\subsection{La dimensión espacial}

Como adelantamos si el análisis temporal cuenta la "película" de la circulación del sentido, el análisis espacial "congela" momentos, saca "fotos" de un proceso que se despliega en el tiempo. También, podría decirse, realiza una serie de close up de momentos significativos. Su objetivo es ilustrar desde otro ángulo las transformaciones del sentido que se producen en la circulación hipermediática. A continuación se van a presentar una serie de gráficos del caso "Massa/Taj ahí" que acabamos de comentar que ilustran los posicionamientos que en diferentes momentos de la circulación distintos enunciadores asumieron en relación a los videos de Sergio Massa. Como hicimos cuando expusimos el análisis temporal, efectuamos primero algunas consideraciones generales.

\subsubsection{Presupuestos del dispositivo analítico para el análisis espacial de la circulación hipermediática}

En los gráficos de análisis espacial se mantiene la disposición que ubica al sistema de medios masivos arriba y a las redes sociales abajo. Se ubica siempre al discurso de referencia, que en el caso que estamos analizando son los videos de Massa, en el centro (D). A partir del discurso de referencia se abre a la izquierda un área de valoración positiva (+) y a la derecha otra de consideración negativa (-). De acuerdo a su vinculo con el discurso de referencia se ubican también los enunciadores, que son los mismos considerados hasta ahora (medios, instituciones, colectivos e individuos). Pero se realizan ciertas precisiones de acuerdo a cómo se ha modificado este campo en la era contemporánea. En el caso de las instituciones principalmente consideramos a las mediatizadas (políticas, judiciales, etcétera), pero si aparecen instituciones aún no mediatizadas (hecho cada vez más difícil dado el alto grado de mediatización de la sociedad contemporánea: ¿qué institución no cuenta, aunque sea, con una cuenta de Twitter o una página en Facebook?) se establece la aclaración pertinente. Medios: distinguimos los masivos (MM) de los digitales (MD). En la primera categoría consideramos obviamente radio, televisión, prensa, etcétera. En la segunda los portales que sólo tienen presencia en la red y los blogs, por ejemplo, pero también manifestaciones digitales de medios masivos existentes. Colectivos: distinguimos otra vez, por un criterio semejante al que utilizamos con las instituciones, a los sociales no mediatizados (CS) de los mediatizados (CSM). Y en cuanto a los individuos diferenciamos individuos profesionales (INDP) de los amateurs (INDA).

\subsubsection{Analisis espacial del caso "Massa/Taj ahí"}

Comenzamos por el gráfico que ilustra espacialmente a la Primera Fase, denominada Emergencia/Deconstrucción. 


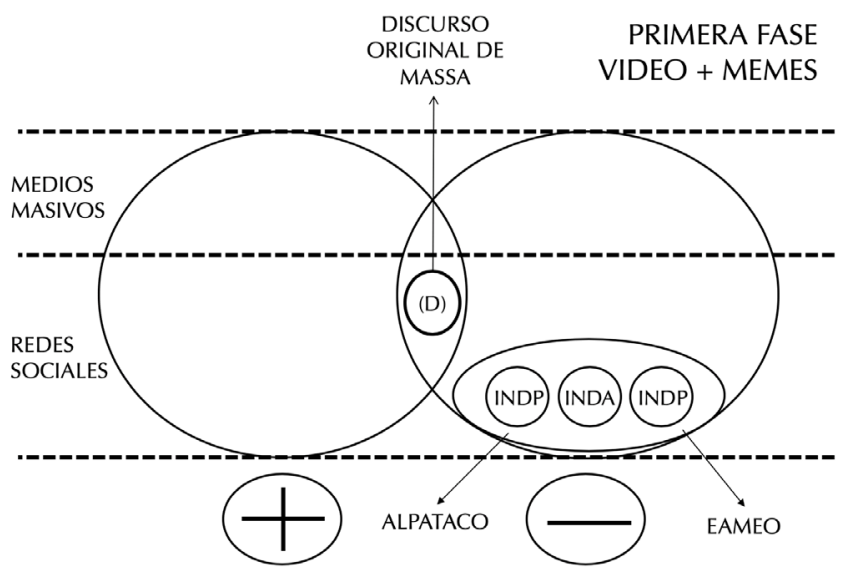

Fonte: Gráfico realizado por Mario Carlón

En el centro, como ya se indicó, se encuentran los videos de Massa (D). A la derecha, con valoración negativa (-), aparecen varios videos identificados de acuerdo quién es el enunciador. Uno de ellos es el de Alpataco, que lo trata como un impostor. Otros son los tweets de distintos enunciadores amateurs más algunos profesionales, como Eameo (una cuenta de Twitter anónima muy conocida).

El siguiente gráfico mantiene a los enunciadores que aparecieron en la Primera Fase y suma lo acontecido en las siguientes subfases, Divulgación y Parodia. En la subfase Divulgacion aparecen dos medios digitales, Infonews, que es un portal de noticias, y Clarin digital (la versión on line de uno de los más importantes matutinos de la Argentina). De la subfase Parodia aparece el video que subió el conductor televisivo Marcelo Tinelli a su canal de YouTube. A todos se los ubica del lado de la valoración negativa (-).

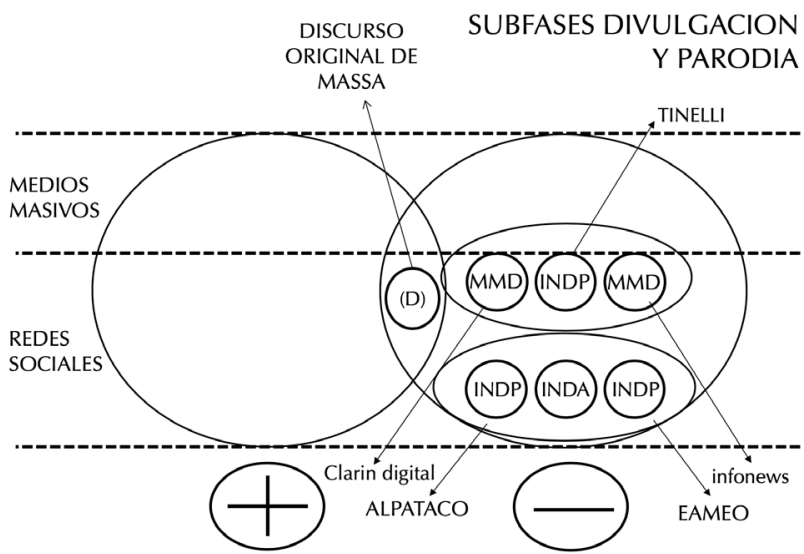

Fonte: Gráfico realizado por Mario Carlón 
Veamos ahora el gráfico de la Segunda Fase, a la que denominamos Interpelación. Incluye el momento en que Massa asiste al programa televisivo y las declaraciones de la conductora, Mirtha Legrand, que es la única que se solidariza con el candidato. Por eso este discurso aparece del lado de la consideración positiva (+).

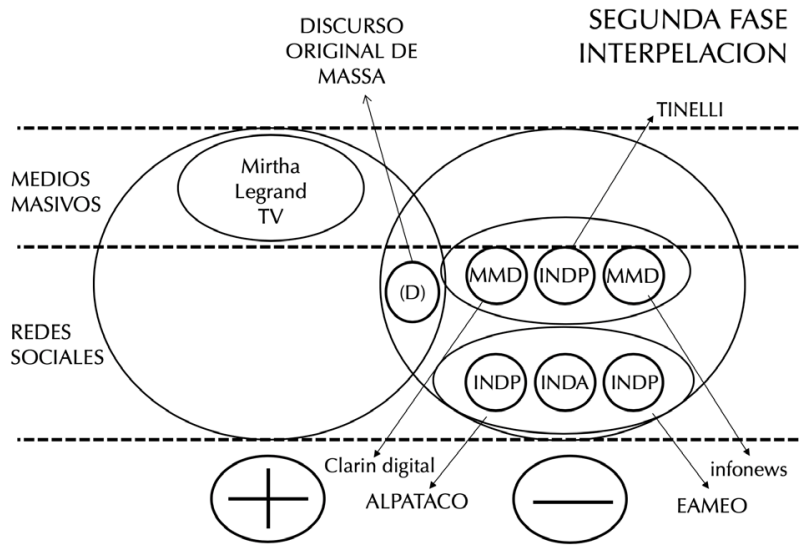

Fonte: Gráfico realizado por Mario Carlón

Finalmente, mostramos un último gráfico que contiene, a la izquierda, el esquema del análisis temporal y, a la derecha, los del análisis espacial que se corresponden con cada Fase o las Subfases.

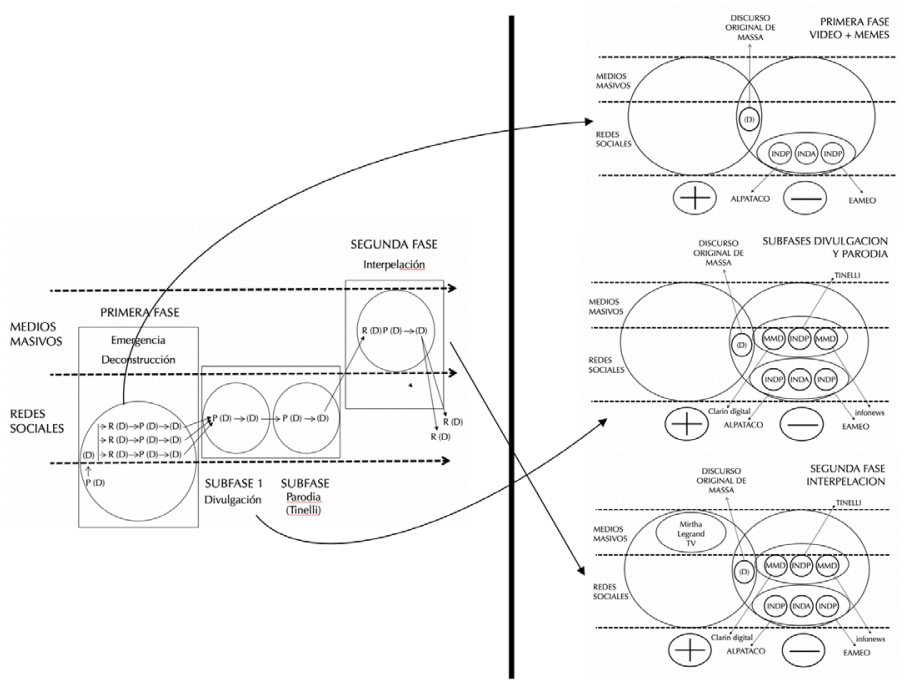


Como comentario final podemos decir que el análisis espacial permite construir escenarios y si bien es especialmente útil para el análisis del discurso político, que construye adversarios, también es operativo para trabajar discursos éticos y estéticos.

\section{Comentarios finales}

Entendemos que el análisis de la circulación del caso que hemos presentado es un aporte para dar cuenta de la situación contemporánea versus anteriores y que, también, nos permite establecer nuevos diálogos con desarrollos teóricos recientes que dan cuenta de nuevos procesos comunicacionales. Decimos esto porque aunque se la denomine de otra forma, la circulación como objeto de estudio es un tema que ha estallado en los últimos años, desde que se consolidó la web2.0 y, por sobre todo, desde la emergencia de las redes sociales mediáticas, que fueron conceptualizadas medios "democráticos" que permiten una comunicación horizontal (un ejemplo de lo que estamos señalando es el conocido y debatido modelo de la "auto-comunicación" de masas propuesto por Manuel Castells, 2012). Otro ejemplo es el campo de estudio de narrativas transmediáticas desarrollado por autores como Henry Jenkins $(2003,2008)$, que focalizan las respuestas que los fans, conceptualizados productores de contenidos, otorgan a las franquicias. Estudios que privilegian casos de circulación descendente seguidos de respuestas ascendentes (desde "abajo hacia arriba").

En este contexto nos gustaría destacar la capacidad de un enfoque semiótico como el que acabamos de presentar para estudiar circulación. No solo porque viene acompañado de una teoría de la mediatización y de una reflexión sobre el estatuto de los enunciadores y los enunciatarios, sino porque gracias a su carácter abstracto y a la sistematización que permiten el análisis espacial y temporal, posee gran capacidad para dar cuenta de distintos tipos de circulación, muchos de ellos no considerados por los estudios actuales. Es lo que sucede con el caso Chicas bondi, al que hicimos referencia en la nota 19, con el caso "Massa/Taj ahí" en el que nos acabamos de concentrar, y con toda una serie diversa de casos que actualmente estamos estudiando.

Para terminar nos gustaría señalar que conceptualizar desde nuestra perspectiva las nuevas forma de circulación de la cultura mediática contemporánea es importante si nos interesa realizar un balance de los aportes y las limitaciones que otras perspectivas presentan. Y para situar, a la vez, qué tipo de aportes desde nuestra mirada se pueden realizar. Porque esos análisis, pese a su relevancia, son insuficientes para dar cuenta de la multiplicidad y complejidad de la circulación actual.

Mario Carlón es doctor en Ciencias Sociales por la Universidad de Buenos Aires. Licenciado en Historia del Arte por la Universidad Nacional de La Plata. Investigador del Instituto Gino Germani de la Facultad de Ciencias 
Sociales de la Universidad de Buenos Aires, donde tiene radicado el Proyecto de Investigación Ubacyt que dirige, "La mediatizacion en el entretejido de los vínculos sociales". Profesor Titular a cargo de Semiótica de Redes en la Carrera de Comunicación en la de la Facultad de Ciencias Sociales de la Universidad de Buenos Aires. Profesor de la Maestría en Comunicación y cultura (FSCO, UBA). Fue Presidente de AsAECA (Asociación Argentina de Estudios sobre Cine y Audiovisual, 2013-2015). Entre otros libros ha publicado: Después del fin. Una perspectiva no antropocéntrica sobre la post-tv, el post-cine y YouTube (Crujia, 2016); junto a Yvana Fechine, O fim da televisão (Confraria do Vento, 2014); en colaboración con Carlos A. Scolari, El fin de los medios masivos. El debate continúa (La Crujía, 2014) y Colabor_arte. Medios y arte en la era de la producción colaborativa (La Crujía, 2012) y con Antonio Fausto Neto, Las políticas de los internautas. Nuevas formas de participación (La Crujía, 2012). También ha publicado Sobre lo televisivo: dispositivos, discursos y sujetos (La Crujía, 2004).

mariocarlon895@gmail.com

\section{Referencias}

CARLÓN, M. La cultura mediática contemporánea: otro motor, otra combustión. (Segunda apropiación de la teoría de la comunicación de Eliseo Verón: la dimensión espacial). A circulação discursiva: entre produção e reconhecimento. In: CASTRO, P. C. (org.). Maceió: Edufal, 2017, pp. 25-48.

. Una apropiación contemporánea de la teoría de la comunicación de Eliseo Verón. In: Comunicación, campo(s) teorías y problemas. Una perspectiva Internacional; Vizer Eduardo y Carlos Vidales (coordinadores), Salamanca, Comunicación social, 2016, pp. 125-153.

Después del fin. Una perspectiva no antropocéntrica sobre la post-tv, el post-cine y YouTube, Buenos Aires, Crujía, 2016, pp. 172.

Público, privado e íntimo: el caso Chicas bondi y el conflicto entre derecho a la imagen y libertad de expresión en la circulación contemporánea", en Dicotomía público/privado: estamos no camino certo? Paulo César Castro (organizador). Maceió: Edufal, 2015, pp. 211-232.

. ¿Del arte contemporáneo a una era contemporánea? Efecto arte y el nuevo valor del presente en la era de Internet, en Estado actual de las mediatizaciones. Florencia Laura Rovetto y María Cecilia Reviglio (comp.). Rosario, UNR Editora, 2014. Disponible en: http://www.cim.unr.edu.ar/archivos/ cuadernodelcim2.pdf

CARLÓN, M. y SCOLARI, C. A. El fin de los medios masivos. En comienzo de un debate. Buenos Aires: La Crujía, 2009. (Segunda edición ampliada: (2014). El fin de los medios masivos. El debate continua. Buenos Aires: La Crujía). 
CASTELLS, M. Comunicación y poder. México: Siglo XXI, 2012.

CINGOLANI, G. Sobre la distinción medio/dispositivo en Eliseo Verón. In: FAUSTO NETO. A.; ANSELMINO, N. R.; GINDIN, I.L. (eds.) Relatos de investigaciones sobre mediatizaciones. Rosario: UNR Editora, 2014, pp. 55-70.

DANTO, A. Tres cajas brillo. Cuestiones de estilo. In: Estética después del fin del arte. Ensayos sobre Arthur Danto. Madrid: Machado Libros, 2005, pp. 19-40.

FAUSTO NETO, A. A circulação alem das bordas. In: FAUSTO NETO, A.; VALDETTARO, S. (org.) Mediatización, sociedad y sentido: aproximaciones comparativas de modelos brasileños y argentinos. Rosario: UNR, 2010, pp. 2-17.

JAKOBSON, R. Lingüística y poética. In: Ensayos de lingüística general. Barcelona: Seix Barral, (1981 [1960]), pp. 347-395.

JENKINS, H. En busca del unicornio de papel: Matriz y la narración transmediática. In: Convergence cultura. La cultura de la convergencia de los medios de comunicación. Barcelona: Paidós.

Transmedia Stroytelling. Moving characters from books to films to video games can make them stronger and more compelling. In: Technology Review, 15 de enero 2003: http://www. technologyreview.com/news/401760/transmedia-storytelling/

JENKINS, H.; FORD, S. y GREEN, J. Cultura da conexão. Criando valor e significado por meio da mídia propagável. São Paulo: Aleph, (2014 [2013]) (Spreadable media: Creating value and meaning in a networked culture, by Henry Jenkins, Sam Ford, and Joshua Green, New York, NYU Press, 2013).

KERBRAT-ORECCHIONI, C. La problemática de la enunciación. In: La enunciación. De la subjetividad en el lenguaje. Buenos Aires: Hachette, (1997 [1986]), pp. 17-44.

$\mathrm{KIM}$, J. The institutionalization of YouYube: from user-generated content to professionally generated content. In: Media, Culture \& Society, Volume 34, issue 1 (January 2012), p. 53-67.

TRAVERSA, O. Aproximaciones a la noción de dispositivo. In: Signo y Seña, 12, Buenos Aires: 2001, pp. 231-247.

VERÓN, E. Teoría da midiatização: uma perspectiva semioantropológica e algumas de suas consequências. In: Revista Matrizes № 1, jan./jun (2014), São Paulo: ECO-USP.

. Lógicas sistémicas sociales y socioindividuales. In: La semiosis social, 2. Ideas, momentos, interpretantes. Buenos Aires: Paidós, 2013, pp. 291-303.

. Ciclos de vida. In: La semiosis social, 2. Ideas, momentos, interpretantes, Buenos Aires: Paidós, 2013, pp. 421-432.

. El fin de la historia de un mueble. In: CARLÓN, M.; SCOLARI, C. A. (ed.). El fin de los medios masivos. En comienzo de un debate. Buenos Aires: La Crujía, 2009, pp. 229-248.

. Prólogo. In: CARLÓN, M. Sobre lo televisivo. Dispositivos, discursos y sujetos. Buenos Aires: La Crujía, (2004), pp. 9-15.

. Esquema para el análisis de la mediatización. In: Diálogos de la Comunicación. №48. Lima: Felafacs, 1997, pp. 9-17.

. La mediatización. In: Semiosis de lo ideológico y el poder/La mediatización. Buenos Aires: FFyL, (1995 [1986]), pp. 39-132.

Mediatización, comunicación política y mutaciones de la democracia. In: Semiosfera 2. 1994, pp. 5-36.

. El sentido como producción discursiva. In: La semiosis social. Fragmentos de una teoría de la discursividad, Buenos Aires: Gedisa, 1987, pp.124-133. 
La palabra adversativa. Observaciones sobre la enunciación política. In: El discurso político. Lenguaje y acontecimientos. Buenos Aires: Hachette, 1987, 13-26.

Posmodernidad y teorías del lenguaje: el fin de los funcionalismos. In: Fragmentos de un tejido. Barcelona: Gedisa, (2004 [1985]), 61-68.

El living y sus dobles. Arquitecturas de la pantalla chica. In: El cuerpo de las imágenes.

Buenos Aires: Norma, (2001 [1984]), pp. 13-40.

Artigo recebido em 29/11/2019

e aprovado em 03/01/2020. 